\title{
A Systematic Review of the Perceived Barriers and Facilitators to Accessing Psychological Treatment for Mental Health Problems in \\ Individuals on the Autism Spectrum
}

\author{
Dawn Adams ${ }^{1,2}, \&$ Kate Young ${ }^{2}$ \\ ${ }^{1}$ Autism Centre of Excellence, Griffith University, \\ Messines Ridge Road, Mt Gravatt, Brisbane, QLD 4122, Australia \\ ${ }^{2}$ Griffith Institute for Educational Research, Griffith University, \\ Messines Ridge Road, Mt Gravatt, Brisbane, QLD 4122, Australia
}

Corresponding author:

Dawn Adams, Autism Centre of Excellence,

Email: Dawn.Adams@Griffith.edu.au

Telephone +61(0)737355854

This is a pre-print copy of an accepted publication. For the full article,

please see Adams, D. \& Young, K. (2020). A Systematic Review of the Perceived Barriers and Facilitators to Accessing Psychological Treatment for Mental Health Problems in Individuals on the Autism Spectrum. Review Journal of Autism and Developmental Disabilities, ePub ahead of Print. https://doi.org/10.1007/s40489-020-00226-7. 


\begin{abstract}
Individuals on the autism spectrum experience high rates of mental health issues. Metaanalyses indicate promising effects of psychological therapies but challenges remain in ensuring and supporting access. This systematic review identified 12 studies that report on the barriers and facilitators to accessing psychological treatments for mental health or emotional/behavioural challenges for individuals on the autism spectrum. The most commonly reported barrier was a lack of therapist knowledge or expertise in autism or an inability or unwillingness on the part of the therapist to tailor approaches to support the needs of those on the autism spectrum. Fewer studies identified facilitators to accessing services. The findings highlight avenues for improving access to mental health services for individuals on the autism spectrum.
\end{abstract}

Keywords: autism, mental health, therapy, intervention, anxiety, behaviour

\title{
Funding
}

This research did not receive any specific grant from funding agencies in the public, commercial, or not-for-profit sectors.

\section{Author contributions:}

Dawn Adams: designed the study, wrote the protocol, coordinated the inter-rater review process, was the third-rater for the review process, screened the full-test articles, extracted and synthesised the data from the included manuscripts, drafted the initial manuscript and finalized the manuscript for submission. 
Kate Young: conducted the systematic review, contributed to the writing of the manuscript, critically reviewed the manuscript, and approved the final manuscript as submitted.

\section{Conflict of interest}

All authors declare that they have no conflicts of interest. 
Autism spectrum disorder (hereafter autism) is a neurodevelopmental condition characterised by differences or difficulties in social communication and the presence of restrictive and repetitive behaviours (American Psychiatric Association, 2013). Many individuals on the autism spectrum will experience co-occurring conditions, one of the most frequently reported being mental health or psychiatric conditions. Meta-analyses suggest prevalence rates of anxiety to be $40 \%$ in children on the autism spectrum (van Steensel et al., 2011) and 27\% in adults on the autism spectrum (Hollocks et al., 2019). Meta-analyses have also reported prevalence rates for depression across adolescents and adults on the autism spectrum of around 11-12\% (e.g., Hudson et al., 2019). A recent umbrella meta-analysis (Lai et al., 2019) combined data from 68 studies and 169,829 participants with a diagnosis on the autism spectrum to suggest a pooled prevalence of $20 \%$ for anxiety disorders across the lifespan. The combined data from 65 studies and 162,671 participants within this metaanalysis also suggested a pooled prevalence of $11 \%$ for depressive disorders for individuals on the autism spectrum. These prevalence rates are notably higher than those reported in general population meta-analyses (general population worldwide pooled prevalence anxiety child/adolescent: $6.5 \%$, lifetime $12.9 \%$; depression child/adolescent $2.6 \%$, lifetime mood disorders 5.4\%; Polanczyk et al., 2015; Steel et al., 2014). There is growing research documenting the impact that mental health difficulties can have on educational outcomes, quality of life, behavioural challenges, family life, employment, and independence above and beyond what is associated with autism (Adams, Clark, \& Keen, 2019; Adams, Young, et al., 2019; <removed for blind review>, den Houting, Adams, Roberts \& Keen, 2020; Mason, Mackintosh, et al., 2019; Robertson et al., 2018). Given these factors, it is unsurprising that developing treatments which can be effective and can be implemented in the real world has been identified as a priority for future research (Vasa et al., 2018). 
To date, the most commonly researched psychological therapy for reducing mental health problems in individuals on the autism spectrum has been cognitive behavioural therapy (CBT) (White et al., 2018). Multiple meta-analyses of CBT for anxiety in children and adolescents on the spectrum report medium to large effect sizes on parent and clinician ratings. The effect size for change on self-report measures of anxiety symptomatology is smaller (Kreslins et al., 2015; Sukhodolsky et al., 2013; Ung et al., 2015). This pattern of larger effect sizes on informant and clinician ratings than on self-report ratings was also noted in the results of a meta-analysis of CBT for individuals on the autism spectrum across all ages (Weston et al., 2016). To date, there have been few studies evaluating the effectiveness of CBT for depression, with randomized evaluations of group-based therapies reporting mixed results (McGillivray \& Evert, 2014; Santomauro et al., 2016; Sizoo \& Kuiper, 2017). This has led to feasibility trials of adaptations such as low-intensity self-help CBT-based intervention for depression (Russell et al., 2017; Russell, Gaunt, et al., 2019). Treatment approaches other than CBT, including mindfulness-based therapies (Gaigg et al., 2020; Sizoo \& Kuiper, 2017), are also showing emerging evidence from individual trials.

Identifying which psychological interventions and specific therapies have emerging and established research evidence for reducing mental health symptomatology is only one step towards reducing mental health problems. Ensuring that individuals are willing and able to access such therapies is critical if such interventions are to be delivered to those who would benefit from them. Poor rates of treatment access have been reported in typically developing individuals across multiple countries. One recent study using National Survey data reported that $47.4 \%$ of children with a mental health problem, and $33.8 \%$ of children with a mental health problem causing severe functional impairment and whose parents perceived that their child needed help, had not seen any health professional in the last 18 months (Sawyer et al., 2019). This need-treatment gap is also reported in adult general 
population worldwide samples, with only $42-44 \%$ of individuals with a mental health problem seeking treatment from specialists or non-specialists in the public or private sectors (Kohn et al., 2004). A need-treatment gap is reported for a range of services for individuals on the autism spectrum of all ages (Taylor \& Henninger, 2015; Schott, Nonnemacher \& Shea, 2020). The service-treatment gap is also reported by providers, with a recent systematic review concluding that American autism-related services were limited in terms of overall numbers, time available, and knowledgeability (McBain et al., 2020).Despite being more likely to experience physical or mental health issues (Fortuna et al., 2016) and to attend more general practitioner or outpatient healthcare visits than age-matched typically developing peers (Weiss et al., 2018; Zerbo et al., 2018), individuals on the autism spectrum report more unmet healthcare needs (Nicolaidis et al., 2013).

This pattern of accessing more services yet reporting unmet healthcare needs may reflect individuals on the autism spectrum (or their families) trying multiple avenues in an attempt to find a provider who has good autism knowledge and uses this knowledge to adapt their approach (Mason et al., 2019). Of course, such reasons cannot be inferred from looking at access statistics alone. Information around barriers and facilitators to accessing services can only be learnt from listening to the experiences of individuals on the autism spectrum and/or their family members. In relation to service access and engagement, barriers can be described as the reasons that prevent or decrease the likelihood of seeking out, accessing or engaging with services (Whittle et al., 2018). In contrast, facilitators are reasons that support or increase the likelihood of seeking out, accessing or engaging with services. A recent systematic review of barriers and facilitators to accessing physical healthcare services for adults on the autism spectrum (Mason et al., 2019) reported on the results of six studies (two qualitative, two quantitative, and two mixed-methods). Across these six studies, three key barriers were identified: patient-provider communication, sensory sensitivities, and executive 
functioning/planning. Whilst this has clear implications for all service providers, this review was only focussed on barriers to accessing physical healthcare and, as such, did not include studies reporting on barriers to services for mental health or behavioural issues. Due to the differing nature of the frequency and content of physical and mental healthcare appointments, the barriers and facilitators may differ.

Reardon et al. (2017) conducted a systematic review of parent-perceived barriers and facilitators of accessing psychological treatment for mental health or emotional/behavioural problems in typically developing children. From their review of 2260 unique records, they identified 410 texts for full-text eligibility. After full-text review, 366 were excluded, with the most common reasons for exclusion being that the study did not specifically address barriers/facilitators $(\mathrm{n}=177)$ or it was focused upon the statistical predictors of helpseeking/service use $(n=97)$. Of the 44 studies deemed to meet inclusion criteria, 20 reported quantitative data, 20 qualitative data and 2 both. The majority of the 20 quantitative papers reported on barriers to accessing mental health services, only two reported on facilitators. All qualitative studies provided data relating to perceived barriers and 13 provided data relating to perceived facilitators. Barriers and facilitators were synthesised into four areas from across the 44 studies: family circumstances, attitudes towards services providers and treatment, knowledge and understanding of mental health problems, and help-seeking process and the mental health system. Their findings suggest that although some issues impact accessing any healthcare service, there are a number of factors which impact upon accessing psychological services specifically. However, Reardon et al.'s review purposefully excluded any studies focusing upon "special populations" (including children on the autism spectrum).

The purpose of this study is therefore to systematically review studies that report on the barriers or facilitators to accessing psychological treatment for mental health or behavioural problems in individuals on the autism spectrum. This review will synthesise both 
quantitative and qualitative studies and include the barriers and facilitators perceived by individuals on the autism spectrum or their parents/caregivers. The review focuses on access to psychological treatments and therapy (rather than medication) and will include the barriers and facilitators to seeking, obtaining, and maintaining help through specialist services.

\section{Method}

The protocol for this systematic review was registered online with PROSPERO, an international register for systematic reviews with health-related outcomes (Registration number: $<$ blinded $>$ ). Preferred Reporting Items for Systematic Reviews and Meta-Analyses (PRISMA) standards were followed for all stages of this systematic review.

\section{Eligibility Criteria}

The inclusion and exclusion criteria for this review required studies to specifically report on the barriers or facilitators experienced by parents or individuals on the spectrum when accessing therapeutic services to support mental health problems. Given that mental health difficulties can often influence behaviour and increase behavioural challenges (Adams, Young, et al., 2019), as per Reardon et al.'s (2017) review, this review included barriers and facilitators to accessing services for broader emotional or behavioural problems. Studies were included within this literature review if they met the following inclusion criteria: (a) study must report on the experiences of barriers or facilitators to accessing treatment for mental health problems, emotional or behavioural problems, or a specific mental health disorder for the individual on the autism spectrum; (b) study must involve a sample of humans with a diagnosis on the autism spectrum and/or their caregivers; (c) if there is a mixed-diagnosis sample, the data for the autism group of interest are reported separately. Reviews, opinions, dissertations, editorials, book chapters, descriptive pieces, and articles written in languages other than English were not included in this systematic review. 
As per reviews of barriers and facilitators of accessing services for typically developing children (Reardon et al., 2017), studies were excluded if they reported only upon the services accessed, statistical predictors of service use/help-seeking behaviour, accessing medication, or inpatient psychiatric care. Those that focussed on services accessed for other reasons or that focussed on services accessed for people other than the individual on the autism spectrum were also excluded. There was no requirement relating to the nature of the mental health or behavioural problem that the individual was seeking support for; studies focusing on either a specific mental health disorder (e.g., depression, anxiety) and/or behaviour and/or emotional problems more generally were included. In contrast to Reardon et al. (2017) who focussed solely on children and adolescents, no limit was placed on the age range of the person seeking the treatment. This a priori decision was made so that barriers and facilitators could be identified that are relevant to both child or adult samples as well as specific to child or adult samples. The limited work in the area may have also limited the ability to identify common barriers or themes if the review focussed upon a narrower age range.

\section{Search Strategy}

The electronic databases ERIC, MEDLINE, PsycINFO, and Web of Science were initially searched in 2018, with an update search conducted mid-2019. The Cochrane library and PROSPERO database were searched to confirm that no other systematic reviews of the current study topic existed or were registered as being in progress. The search was restricted to articles in English and those published after 1994, when Asperger's disorder was entered into the DSM-IV. Grey and non-peer reviewed literature was excluded. The search strategy included terms pertaining to barriers and facilitators, services or treatments accessed, mental health or emotional/behavioural problems, and autism (see Table 1). The terms in the barriers 
and facilitators and the services/treatments access groups included, but also expanded upon, the terms used for a similar review in typically developing children (Reardon et al., 2017).

Table 1

Search Strategy

\begin{tabular}{llll}
\hline Barriers and & Services or treatments & Mental health or & Autism \\
facilitators & accessed & emotional/behavioural & \\
& & problems & \\
& & & \\
\hline Barrier* OR & Service* OR Treatment* & Mental* OR disorder* & Autis* OR \\
Hurdle OR & OR Therap* OR Support & OR psycho* OR & Asperger* OR \\
Obstruct* OR & OR Help seek* OR Help- & "behavio* problems" & asd OR pdd \\
Obstacle OR & seek* OR "seek* Help" & OR Internali* OR & OR pervasive \\
Promot* OR & OR "care seeking" OR & Anxi* OR Affect* OR & developmental \\
Facilitat* OR & "seek* care" OR "access & Depress* OR Suicid* & disorder \\
Encourage* OR & treatment" OR "access & OR Externali* OR & \\
$\begin{array}{l}\text { Support* OR } \\
\text { Cause* OR }\end{array}$ & service" OR "seek* & ADHD OR "self & \\
Predict* OR & treatment" OR "service* & harm" OR & \\
"Unmet need" OR & use" OR "service* & oppositional OR & \\
Hinder OR & utilisation" OR "service* & conduct OR emotion* & \\
Willingness OR & participation" OR & & \\
Enable* & "treatment engagement" & & \\
\hline
\end{tabular}

* Search strings were connected by the Boolean Operator "AND”.

\section{Review Strategy}

When combined, the electronic searches conducted in 2018 and 2019 resulted in 33,006 records being identified (see Figure 1). Following removal of duplicates, the titles and abstracts of 21,141 articles were assessed against inclusion criteria by the primary rater, and a random sample of $20 \%$ was double reviewed by a second rater who was blind to the other researcher's ratings. This is accepted practice when a review is large and resources are limited (Petticrew \& Roberts, 2008). The double reviewing resulted in a 99.9\% agreement (Kappa $>.9)$. The $86(0.4 \%)$ articles where the ratings differed were screened by a third rater who casted the deciding vote. 
Where inclusion or exclusion could not be determined by the title and abstract alone, the full text of 274 articles was assessed by a primary rater. A random sample of $20 \%$ of these were double reviewed by a second rater blind to the other researcher's ratings. There were no disagreements at this stage. Once studies were identified as meeting inclusion criteria, a forward and backward citation search was conducted at the end of 2019 to ensure no relevant research had been missed. One additional study was found that met inclusion criteria (Jackson et al., 2020), resulting in 12 studies that met the criteria for the current review.

++ Insert Figure 1 here++

\section{Data Extraction and Synthesis}

For each paper, information recorded included details of the research team (including geographical location of study), study design (e.g., questionnaire, interview), sample characteristics (including the informant), and barriers and facilitators identified.

\section{Assessment of Study Quality}

Studies included in the final data synthesis were evaluated for methodological quality using the Quality Assessment Tool for Studies with Diverse Designs (QATSDD; Sirriyeh et al. 2012). The QATSDD is a 16-item tool that can be used to evaluate the quality of quantitative, qualitative, or mixed-method studies. Fourteen of the criteria apply to qualitative studies (maximum score 42), 14 apply to quantitative studies (maximum score 42) and all 16 apply to any mixed methods papers (maximum score 48). This measure was developed by firstly applying a multi-method quality assessment tool (Jackson et al., 2008) to a range of qualitative, quantitative and mixed methods studies, noting its strengths, limitations and areas not assessed. Secondly, a comprehensive list of elements which represented good research design was extracted from other quality assessment tools specifically for quantitative or qualitative studies. The results of these two processes were combined with consultations with 
senior academic researchers from a number of Universities as well as an expert from the York Centre for Reviews and Dissemination. The resulting QATSDD was then piloted, revealing good inter-rater reliability $(\mathrm{k}=71.5 \%)$. The QATSDD has been used in autismfocused systematic reviews, including those on quality of life (Ayres et al., 2018), autism symptomatology in specific syndromes (Wolfenden et al., 2017), autism knowledge (McCormack et al., 2020) and therapeutic interventions (Byrne et al., 2020). As per Mason, Ingham, et al.'s (2019) review of barriers and facilitators to physical healthcare for adults on the autism spectrum, the QATSDD rating was informative rather than part of the inclusion or exclusion criteria.

\section{Results}

\section{Included Papers}

Overall, 12 papers were included in the review, and these are summarised in Table 2. Of these, three reported on barriers/facilitators to services for behavioural challenges and nine for mental health services. The 12 papers were published in seven different journals. Journals which had more than one paper included in the review were Autism $(n=3)$, Journal of Child and Family Studies $(n=3)$ and Journal of Autism and Developmental Disorders $(n=2)$. 
Table 2

Studies Included in the Review

\begin{tabular}{|c|c|c|c|c|c|c|c|c|}
\hline Study & $\begin{array}{c}N \\
\text { Respondent }\end{array}$ & $\begin{array}{c}\text { Age } \\
\text { (mean, sd, } \\
\text { range) }\end{array}$ & $\%$ male & $\begin{array}{c}\text { Study } \\
\text { design and } \\
\text { country }\end{array}$ & $\begin{array}{l}\text { Additional } \\
\text { diagnoses of } \\
\text { individual with } \\
\text { autism, } \\
\text { medication }^{1}\end{array}$ & $\begin{array}{l}\text { Sampling } \\
\text { technique }\end{array}$ & Service & Barriers/Facilitators identified \\
\hline $\begin{array}{l}\text { Anderson } \\
\text { et al. } \\
(2019)\end{array}$ & $\begin{array}{c}102 \\
\text { Adults on } \\
\text { spectrum }\end{array}$ & $\begin{array}{c}18-24 y: \\
65 \% \\
25 y+: 35 \%\end{array}$ & 69 & $\begin{array}{l}\text { Online } \\
\text { survey } \\
\text { Australia }\end{array}$ & $\begin{array}{c}\text { Anx } 68 \% \\
\text { Dep } 40 \% \\
\text { ADHD/ADD } \\
30 \% \\
\text { Other } 27 \%\end{array}$ & $\begin{array}{l}\text { Online } \\
\text { Through } \\
\text { university } \\
\text { disability } \\
\text { services }\end{array}$ & $\begin{array}{l}\text { Anxiety/stress } \\
\text { management } \\
\text { Counselling } \\
\quad \text { for } \\
\text { depression }^{2}\end{array}$ & $\begin{array}{l}\text { Barriers: Service not available (16\% for anxiety } \\
\text { management, } 5 \% \text { for counselling) or access } \\
\text { limited by individual's poor advocacy }(34 \% \text { for } \\
\text { anxiety management, } 18 \% \text { for counselling) } \\
\text { Facilitators: none reported }\end{array}$ \\
\hline $\begin{array}{l}\text { Anderson } \\
\text { et al. } \\
(2018)\end{array}$ & $\begin{array}{c}20 \\
\text { Parents }\end{array}$ & $\begin{array}{l}\text { Parent: } \\
55.4(4.8) \\
\text { Child: } \\
24(3.5)\end{array}$ & $\begin{array}{l}\text { Parents: } \\
\quad 85 \\
\text { Child: } \\
\quad 75\end{array}$ & $\begin{array}{l}\text { Semi- } \\
\text { structured } \\
\text { interviews } \\
\text { USA }\end{array}$ & ID $8 \%$ & $\begin{array}{l}\text { Autism } \\
\text { advocates and } \\
\text { personal } \\
\text { contacts of } \\
\text { researcher }\end{array}$ & Mental health & $\begin{array}{l}\text { Barriers: "batted back and forth" between ID } \\
\text { and mental health services, therapist does not } \\
\text { have expertise to treat mental health in autism } \\
\text { Facilitators: none reported }\end{array}$ \\
\hline $\begin{array}{l}\text { Camm- } \\
\text { Crosbie et } \\
\text { al. }(2019)\end{array}$ & $\begin{array}{l}200 \\
\text { Adults on } \\
\text { the } \\
\text { spectrum }\end{array}$ & $\begin{array}{c}38.9(11.5) \\
18-67 y\end{array}$ & 59 & $\begin{array}{c}\text { Online } \\
\text { survey } \\
\text { (open } \\
\text { questions) } \\
\text { UK }\end{array}$ & $\begin{array}{c}\text { Dep } 88.8 \% \\
\text { Anx } 79.3 \% \\
\text { Other } 22.3 \%\end{array}$ & $\begin{array}{l}\text { Autism } \\
\text { research } \\
\text { database, } \\
\text { charities, } \\
\text { support } \\
\text { groups, } \\
\text { educational } \\
\text { institutions, } \\
\text { and social } \\
\text { media }\end{array}$ & Mental health & $\begin{array}{l}\text { Barriers: falling between "gaps" in services } \\
(18.5 \%) \text {, dismissed and seen as "coping" }(13 \%) \text {, } \\
\text { support geared towards children and their } \\
\text { parents (not adults) }(4.5 \%) \text {, long waiting lists } \\
\text { and lack of funding }(18.5 \%) \text {, professionals' lack } \\
\text { of understanding and knowledge of autism and } \\
\text { how it impacts therapy ( } 45 \%) \text {, challenges with } \\
\text { self-acknowledgement of the need for treatment } \\
(17 \%) \text {, lack of tailoring of therapy to autism } \\
\text { profile }(19 \%) \text {, felt symptoms not believed or } \\
\text { listened to }(14.5 \%)\end{array}$ \\
\hline
\end{tabular}




\begin{tabular}{|c|c|c|c|c|}
\hline \multirow{2}{*}{$\begin{array}{l}\text { Chiri \& } \\
\text { Warfield } \\
\text { (2012) }\end{array}$} & $\begin{array}{c}2,088 \\
\text { Parents }\end{array}$ & $\begin{array}{l}\text { Parent: } \\
\text { N/S }\end{array}$ & $\begin{array}{l}\text { Parent: } \\
\text { N/S }\end{array}$ & $\begin{array}{c}\text { Telephone } \\
\text { survey }\end{array}$ \\
\hline & & $\begin{array}{c}\text { Child: } \\
3-5 y \\
18.9 \% \\
6-11 y \\
42.1 \% \\
12-17 y \\
39.1 \%\end{array}$ & $\begin{array}{l}\text { Child: } \\
79\end{array}$ & USA \\
\hline $\begin{array}{l}\text { Crane et } \\
\text { al. }(2019)\end{array}$ & $\begin{array}{c}21 \\
\text { Adults on } \\
\text { the } \\
\text { spectrum }\end{array}$ & $\begin{array}{c}20.9(3.0) \\
16-26\end{array}$ & 43 & $\begin{array}{c}\text { Focus } \\
\text { groups } \\
\text { UK }\end{array}$ \\
\hline $\begin{array}{l}\text { Hock et } \\
\text { al. }(2015)\end{array}$ & $\begin{array}{c}13 \\
\text { Parents }\end{array}$ & $\begin{array}{c}\text { Parent: } \\
\text { N/S } \\
\\
\text { Child: } \\
4.6(1.3) \\
2-7\end{array}$ & $\begin{array}{c}\text { Parents: } \\
23 \\
\text { Childre } \\
\text { n: } \\
\text { N/S }\end{array}$ & $\begin{array}{c}\text { Interview } \\
\text { USA }\end{array}$ \\
\hline
\end{tabular}

Facilitators: continuity of care and therapist $(6 \%)$, therapist knowledge about mental health in autism, therapist being flexible and making adaptations to meet needs

\section{Special care \\ health \\ Randomly
sampled}

needs: $100 \%$

\section{Existing} database

Social media

Personal

contacts of

research team

$\mathrm{N} / \mathrm{R}$

\section{Parents who \\ had}

participated

in

intervention
Mental health Barriers: costs too much (18\%), service not available within area/transportation $(16.8 \%)$, provider does not accept insurance (16.6\%), dissatisfaction with provider (14.2\%), provider did not know how to treat ${ }^{+}(13.6 \%)$, did not know where to go $(12.8 \%)$

Facilitators: none reported

Mental health
Behaviour

Barriers: problems not deemed "severe enough for support", delays in being able to access, services not tailored to needs associated with autism or coordinating with each other, limited sessions or funding withdrawn, "bounced between systems"

Facilitators: therapists listening to the person on the spectrum as to what will/will not work, remaining in child services for as long as possible

Barriers: distance of treatment from home, personal, work, and school schedules

Facilitators: therapist effectiveness and delivery, therapist having a personal connection to autism 


\begin{tabular}{|c|c|c|c|c|c|c|c|c|}
\hline $\begin{array}{l}\text { Jackson et } \\
\text { al. }(2020)\end{array}$ & $\begin{array}{c}7 \\
\text { Parents }\end{array}$ & $\begin{array}{l}\text { Parent: } \\
42.7(4.2) \\
\text { Child: } \\
12.9(1.3)\end{array}$ & $\begin{array}{l}\text { Childre } \\
\text { n: } 43\end{array}$ & $\begin{array}{l}\text { Interview } \\
\text { UK }\end{array}$ & $\begin{array}{l}\text { ADHD } 14 \% \\
\text { ODD } 14 \% \\
\text { Self-harm } 71 \%\end{array}$ & $\begin{array}{l}\text { Support } \\
\text { group }\end{array}$ & Mental health & $\begin{array}{l}\text { Barriers: long waiting times }(100 \%) \text {, "fighting to } \\
\text { be heard" }(100 \%) \text {, rejection/not meeting service } \\
\text { criteria }(85 \%) \text {, broken trust with services and/or } \\
\text { therapist } \\
\text { Facilitator: continuity of therapist and sessions } \\
(100 \%)\end{array}$ \\
\hline $\begin{array}{l}\text { Lipinski et } \\
\text { al. (2019) }\end{array}$ & $\begin{array}{l}262 \\
\text { Adults on } \\
\text { the } \\
\text { spectrum }\end{array}$ & 37 (12) & 62 & $\begin{array}{l}\text { Online } \\
\text { survey } \\
\text { Germany }\end{array}$ & $\begin{array}{c}\text { Dep } 60 \% \\
\text { Phobia } 27 \% \\
\text { Eating disorder } \\
14 \% \\
\text { None } 23 \%\end{array}$ & $\begin{array}{l}\text { Mailing list, } \\
\text { support } \\
\text { groups, } \\
\text { forums }\end{array}$ & Mental health & $\begin{array}{l}\text { Barriers: lack of knowledge of } \\
\text { diagnosis/syndrome }^{+}(43.3 \%) \text {, long waiting } \\
\text { times }^{+}(40 \%) \text {, unable to make first contact in } \\
\text { preferred way }(26.7 \%) \text {, overwhelmed by search } \\
\text { for therapy place }(3.4 \%) \\
\text { Facilitators (rating } 1-7 \text {, not important to very } \\
\text { important): } \\
\text { a low-stimulus environment during sessions } \\
\text { (5.9), clear structure of sessions }(5.8) \text {, able to } \\
\text { communicate with the psychotherapist in written } \\
\text { form }(5.7) \text {, regular time, place, and room }(4.5)\end{array}$ \\
\hline $\begin{array}{l}\text { McMorris } \\
\text { et al. } \\
(2018)\end{array}$ & $\begin{array}{l}45 \\
\text { Adults on } \\
\text { the } \\
\text { spectrum }\end{array}$ & $\mathrm{N} / \mathrm{R}$ & 82 & $\begin{array}{l}\text { Interview } \\
\text { Canada }\end{array}$ & $\begin{array}{c}\text { Anx } 31 \% \\
\text { Dep } 24 \% \\
\text { Learning } \\
\text { disorder } 22 \% \\
\text { ADHD } 11 \% \\
1+\text { mental } \\
\text { health } \\
\text { diagnosis } 56 \%\end{array}$ & $\begin{array}{l}\text { Enrolled in } \\
\text { academic } \\
\text { mentorship } \\
\text { program }\end{array}$ & Mental health ${ }^{2}$ & $\begin{array}{l}\text { Barriers: desire to handle it alone, long waiting } \\
\text { times, steps to access overwhelming, difficulties } \\
\text { describing problems or needs } \\
\text { Facilitators: none reported }\end{array}$ \\
\hline $\begin{array}{l}\text { Mello et } \\
\text { al. (2016) }\end{array}$ & $\begin{array}{c}415 \\
\text { Parents }\end{array}$ & $\begin{array}{l}\text { Parent: } \\
\text { N/S } \\
\text { Child: } \\
10.9(5.8)\end{array}$ & $\begin{array}{l}\text { Parents: } \\
13 \% \\
\text { Childre } \\
\text { n: N/S }\end{array}$ & $\begin{array}{c}\text { Online and } \\
\text { paper } \\
\text { Survey } \\
\text { USA }\end{array}$ & $\mathrm{N} / \mathrm{R}$ & $\begin{array}{c}\text { Flyers, } \\
\text { emails, } \\
\text { support } \\
\text { groups, } \\
\text { websites, } \\
\text { parent } \\
\text { newsletters }\end{array}$ & Behaviour $^{2}$ & $\begin{array}{l}\text { Barriers: service not available in area }(61.9 \% \text { in } \\
\text { rural and } 22.2 \% \text { in non-rural areas }) \\
\text { Facilitators: none reported }\end{array}$ \\
\hline
\end{tabular}




\begin{tabular}{|c|c|c|c|c|c|c|c|c|}
\hline $\begin{array}{l}\text { Raulston } \\
\text { et al. } \\
(2019)\end{array}$ & $\begin{array}{c}30 \\
\text { Parents }\end{array}$ & $\begin{array}{l}\text { Parent: } \\
37.4 \\
\text { Child: } \\
6.8(2.6)\end{array}$ & $\begin{array}{c}\text { Parent: } \\
13 \%\end{array}$ & $\begin{array}{l}\text { Online } \\
\text { semi- } \\
\text { structured } \\
\text { focus } \\
\text { groups } \\
\text { USA }\end{array}$ & $\mathrm{N} / \mathrm{R}$ & $\begin{array}{l}\text { Flyers, social } \\
\text { media }\end{array}$ & Behaviour & $\begin{array}{l}\text { Barriers/Facilitators: cost, } \\
\text { supportive professional with } \\
\text { expertise in CB; accessible flexible options (to } \\
\text { fit into schedule), }\end{array}$ \\
\hline $\begin{array}{l}\text { Tint \& } \\
\text { Weiss } \\
(2018)\end{array}$ & $\begin{array}{l}20 \\
\text { Adults on } \\
\text { the } \\
\text { spectrum }\end{array}$ & $\begin{array}{c}35.5(12.3) \\
19-69 y\end{array}$ & $0^{3}$ & $\begin{array}{l}\text { Focus } \\
\text { groups } \\
\text { Canada }\end{array}$ & $\mathrm{N} / \mathrm{R}$ & $\begin{array}{l}\text { Website } \\
\text { Email list }\end{array}$ & Mental health ${ }^{2}$ & $\begin{array}{l}\text { Barriers: cost/funding, services/therapists not } \\
\text { adapting to the needs associated of those on the } \\
\text { spectrum, difficulties describing/identifying } \\
\text { emotions, therapists being unawareness of } \\
\text { impact of autism on therapy } \\
\text { Facilitators: none reported }\end{array}$ \\
\hline
\end{tabular}

${ }^{1}$ If not listed then not reported in article.

${ }^{2}$ Article reported on experience in accessing a broader range of services but only the barriers or facilitators for behaviour or mental health services are reported here.

${ }^{3}$ This study was specifically focusing on the services experiences of women on the autism spectrum.

${ }^{+}$Barrier significantly higher for those with a diagnosis of autism than comparison group.

Key (alphabetical): $\mathrm{ADD}=$ Attention Deficit Disorder, $\mathrm{ADHD}=$ Attention Deficit Hyperactivity Disorder, Anx $=$ Anxiety, $\mathrm{CB}=\mathrm{challenging}$ behaviour, Dep = Depression, ID = Intellectual Disability, N/R = Not reported, ODD = Oppositional Defiant Disorder 


\section{Research Team and Study Design}

The research was conducted in five countries: the United States $(n=5)$, United Kingdom $(n=3)$, Canada $(n=2)$, Germany $(n=1)$, and Australia $(n=1)$. For a summary of the organisation and funding scheme for each country's health system, see data from the Commonwealth Fund (2020). All of the studies focussing on services for behavioural challenges were undertaken in the United States. Four studies used quantitative methodology. Two studies collected survey data solely online (Anderson et al., 2019, Lipinski et al., 2019), one used an online survey but also offered paper copies (Mello et al., 2016), and one collected data through a national telephone survey (Chiri \& Warfield, 2012). Eight studies used qualitative methodology, with four using interviews (Anderson et al., 2018, Hock et al., 2015, Jackson et al., 2020, McMorris et al., 2018), three using focus group methodologies (Crane et al., 2019, Raulston et al., 2019; Tint \& Weiss, 2018), and one analysing open-ended written responses from an online questionnaire (Camm-Crosbie et al., 2019).

\section{Participants}

Sample sizes ranged from 102 to 2,088 for those that used surveys, and from 7 to 59 for the qualitative studies (interview/focus/open-ended written answers methodologies). The study with the largest sample size was understandably that which used the national surveybased study ( $n=2,088$, Chiri \& Warfield, 2012). The average percentage of males was $52.5 \%$ for those reporting on self-report from adults on the spectrum as respondents. Only three of the parent-report studies reported on the gender of the children, resulting in an average of $65.7 \%$ males.

Co-occurring diagnoses were reported in eight of the 12 studies. None of the studies exploring access to behavioural services, and only one study exploring access to mental health services, reported on the proportion of individuals on the spectrum who had a cooccurring intellectual disability (Anderson et al., 2018). Not all of the studies exploring 
access to mental health services reported on the mental health diagnoses of the individuals on the spectrum. None of the studies independently confirmed the autism diagnoses of participants using standardised direct assessment methods or informant interviews. One study used a screening questionnaire of autism characteristics (Crane et al., 2019; Social Responsiveness Scale) to support diagnosis. Of the remaining studies, four asked the adult self-reporting participant to confirm/provide formal diagnosis given, three asked parents just to confirm their child had a diagnosis, two relied on parent-report of the child's diagnosis received, and one did not state how the diagnosis was confirmed.

\section{Methodological Quality}

Ratings on the QATSDD highlighted methodological strengths and limitations of the studies. Overall, studies were designed with clear aims and data were collected and analysed using appropriate methods to meet those aims. Of note is that six studies reported involvement of users in the design and/or analysis of the study, for example Camm-Crosbie et al. (2019) co-developed their survey with a steering group of eight adults on the autism spectrum. Crane et al. (2019) also reported that the research itself was conducted by individuals on the autism spectrum and two academic researchers who "collaborated - as full and equal partners - during all stages (design, implementation, analysis, interpretation and dissemination) of the research" (p. 478). However, few studies explicitly stated their theoretical framework, few quantitative studies reported psychometrics of their questionnaires, and not all of the qualitative studies shared their interview or focus group schedule or reported reliability checks at all stages of analysis.

\section{Results of Studies}

\section{Quantitative Self-Report Studies}

Two studies conducted online surveys with adults on the autism spectrum which were analysed quantitatively. Anderson et al. (2019) conducted an online survey of Australian 
university students on the spectrum, asking about the use and reasons for non-use of academic and non-academic supports offered by the university. The majority $(64.2 \%)$ of the 95 students had not used "stress or anxiety management" supports, with the most frequently endorsed reasons being poor advocacy (not knowing how to ask for help; 34\%), the service was not needed (25\%), or the service was not available (16\%). Similarly, $61.1 \%$ had not accessed "counselling (depression/mood)" services, with 57\% reporting that the service was not needed, $18 \%$ reporting a barrier of poor self-advocacy, and only $5 \%$ stating that the service was not available. Later in their survey, Anderson et al. (2019) asked further questions about access to mental health services in general (i.e., not specific to the university) since starting university. More than half of the respondents $(n=45,58 \%)$ reported accessing support for depression, while nearly three quarters $(n=55,71 \%)$ had accessed support for anxiety. The most common reason reported for not using support for mental health issues was that the respondent did not need it (depression: $n=19,58 \%$; anxiety: $n=10,45 \%$ ). Fewer than $10 \%$ of the respondents indicated that they didn't access these services because they thought it would not help, that they did not know how to ask for support, that they were worried about the cost, or that that service was not available. None reported worrying about the stigma of disclosing a mental health issue.

Lipinski et al. (2019) reported on barriers to accessing outpatient psychotherapy (psychodynamic psychotherapy, cognitive behavioural therapy, and psychoanalysis) after a diagnosis of a mental health condition was made. The overall sample consisted of 262 adults on the autism spectrum without intellectual impairment and 304 non-autistic controls with major depressive disorder. Participants were given eight options (created by a participatory research group comprising of members of the autism community) to which they could state yes/no and were provided with an additional open entry field to write their own barriers (which no participants used). The most frequently endorsed reasons for not continuing to 
access psychotherapy among individuals on the spectrum were "the psychotherapist did not have any experience with my diagnosis/syndrome" (43.3\%), "the psychotherapist lacked the capacity/the waiting list was too long" (40\%), and "I was not able to initiate first contact in the way I wanted" (26.7\%). All of these were endorsed significantly more often in participants with a diagnosis of autism than in those with a diagnosis of major depressive disorder. Lipinski et al. also reported on participants' ratings of the importance of adjustments to therapy (rated on a scale ranging from 1 [not important] to 7 [very important]). These adjustments may be seen as facilitators to starting and continuing sessions. All five adjustments developed by the participatory group were rated as significantly more important by participants on the spectrum than by those with major depressive disorder. The three adjustments with average scores above 5 were "a low-stimulus environment during sessions" (mean rating 5.9), "a clear structure of the sessions" (mean rating 5.8), and "to be able to communicate with the psychotherapist in written form as well" (mean rating 5.7).

\section{Quantitative Parent-Report Studies}

Two studies conducted questionnaire studies with parents. Chiri and Warfield (2012) used data from the USA National Survey of Children with Special Care Health Needs (NSCSHCN), a telephone survey, which resulted in 2,088 responses from parents of children with special care health needs and a diagnosis of autism. Responses were also collected from parents of children without autism (with other special healthcare needs). Parents were asked to state if they had encountered a specific set of problems when attempting to access core medical services (one of which was mental health services) in the last 12 months. The authors classified the problems into two areas, health-plan-based access problems and provider-based problems. The most endorsed health-plan problem areas were "costs too much" (18\%), "provider does not accept insurance" (16.6\%), and "health plan problem" (11.5\%). The most 
commonly endorsed provider-based problems were "not available in area/transportation" (16.8\%), "dissatisfaction with provider" (14.2\%), and "provider did not know how to treat" (13.6\%). Across both areas, the only barrier which was higher in those with a diagnosis of autism than in those without was "provider did not know how to treat". The second questionnaire study reporting on parent data was Mello et al. (2016), who reported on data from 415 parents in the United States. Parents were asked about which services had been recommended to them and, if they had not accessed them, the reasons why. Rural and nonrural families rated behaviour support services as the most needed service for their child on the autism spectrum. When asked the reasons for not implementing behavioural support services, $61.9 \%$ of those in rural and $22.2 \%$ of those in non-rural areas stated that the service was not available in their area.

\section{Qualitative Self-Report Studies}

Four studies used qualitative analysis of data from adults on the autism spectrum, all of which focused upon access to mental health services. Camm-Crosbie et al. (2019) used thematic analysis to analyse responses to free-text questions on their online survey. The overarching theme was that treatment tailored to the needs of those on the spectrum is both beneficial and desirable. The subtheme of "people like me don't get support" highlighted the challenges of falling between the gaps in services (reported by $18.5 \%$ of participants) or being seen as "coping" and not in need of support (13\%). It also includes the barriers of services having long waiting lists and a lack of funding (18.5\%), not having access to treatment within the local area (6\%), and support being geared towards children and their parents (4.5\%). The subtheme of "lack of knowledge and understanding" described professionals' lack of knowledge of autism and how it can impact upon communication and therapy (44.5\%). It also highlighted how a lack of understanding or communication can present as a challenge in adults on the spectrum recognising their own need for therapy (17\%) 
or being able to explain their need to another person. This subtheme also included descriptions of the lack of tailoring the therapeutic approaches to autism (19\%) and how adults on the spectrum felt their mental health symptoms were discarded (14.5\%), which led to a lack of trust in therapists $(9.5 \%)$. Within this theme, continuity of care and therapist was noted as beneficial by $6 \%$ of participants. Although not reported on in the results, in the discussion, Camm-Crosbie et al. (2019) stated two additional facilitators: clinicians being both knowledgeable about mental health in autism and flexible in order to make reasonable adaptations to meet autistic people's needs. However, it is not known how many participants reported these facilitators.

Crane et al. (2019) conducted interviews with 21 adults on the autism spectrum, exploring (amongst other areas) their experiences of mental health problems and the associated support received. Using thematic analysis, the theme of "barriers to support" for services relating to both autism and mental health was highlighted. The individuals on the autism spectrum felt there was a general lack of available services, in relation to both autism and mental health. Additionally, many individuals said their mental health problems were not deemed "quite severe enough" even when they had received a formal mental health diagnosis, or they said that they were "bounced" between services. When support was available, there were long waiting lists or services were not tailored to the needs of an individual on the spectrum and/or did not have a coordinated approach. There were also implications around the limited number of sessions and funding being withdrawn. Although facilitators were not specifically reported, some participants spoke of how they were aware of what would and would not work for them and were pleased when this was taken into consideration. Others noted benefits of being able to stay within the child mental health service for as long as possible before transitioning into adult mental health services. 
McMorris et al. (2018) interviewed 45 adults on the spectrum enrolled into an academic mentorship program in a Canadian post-secondary setting. During their initial interview into this program, they were asked about mental health supports they were accessing, any services they would like or need for their mental health but were not receiving, and if so, why they were not receiving this service. Participants were presented with a list of 11 possible barriers but were also allowed to provide their own response if needed. Eighteen students $(40 \%)$ were not able to access a service they would like or need for their mental health. Although numbers or percentages endorsing each response was not given, the authors noted the most commonly endorsed reason for not accessing a service was a desire to handle the situation on their own. Long wait times for services, and the steps to accessing services were too overwhelming were also commonly endorsed reasons. Many students also noted challenges in describing their problems or needs to healthcare providers as a factor which precluded them from accessing services.

Tint and Weiss (2018) conducted focus groups with 20 women on the spectrum to explore their experiences of any services and supports, although only data specific to services for mental health are summarised within this review. Several women described their inability to access mental health supports due to their limited financial means and the unavailability of funded supports. The participants also described experiences with mental health professionals being unable or unwilling to adapt their therapeutic approaches to meet the needs of women on the spectrum in either individual or group therapy. They also noted challenges in being able to describe their own emotions to therapists, and some therapists being insensitive or unaware of these challenges.

\section{Qualitative Parent-Report Studies}

Four studies used qualitative approaches with parents of children on the spectrum, of which two reported data relating to mental health services and two focused on access to 
services for behaviour. Anderson et al. (2018) interviewed 20 parents of young adults on the spectrum about their child's transition out of high school in the United States. As part of this, parents spoke about challenges accessing mental health services. They described being "batted back and forth" between mental health and intellectual disability services, and recalled providers stating they do not have the expertise to treat mental health problems in individuals on the spectrum. Jackson et al. (2020) interviewed seven mothers of adolescents on the spectrum who were referred for mental health services. The authors note that "the resounding narrative from all mothers" was one of negative experiences in accessing services. Even once services were accessed, parents recalled a negative experience with the professional experience on offer. All mothers (100\%) reported long waiting times without support or advice, having to fight to be heard, and six (85\%) mothers reported feeling rejected when service criteria were not met or when therapy was ended after only a few sessions. A number of parents spoke about a loss of trust in the therapist and the impact this had on their child's therapy. All (100\%) parents noted the importance of continuity to build trust between the child and the therapist.

Hock et al. (2015) interviewed 13 parents of young children on the spectrum who had been invited to a weekly parent group on behavioural principles and parenting approaches for children on the spectrum. Three parents interviewed had declined to attend the parent group, four had completed four or five sessions, and six had completed all six sessions. Parents identified the lack of contact by the therapist following non-attendance, as well as external factors such as the distance of treatment from home and personal, work, or school schedules, as barriers to accessing the treatment offered. Parents who attended and remained in the group spoke of the effectiveness of the therapist's delivery of material (including visual aids) and that the disclosure by one of the therapists that her own son had a diagnosis on the autism spectrum helped to sustain their attendance and engagement in the sessions. Raulston et al. 
(2019) used "Google Hangouts" to conduct semi-structured online focus groups with parents of children on the autism spectrum to discuss variables that enable and those that pose barriers to parental engagement in behavioural interventions. The descriptive labels of their themes are labelled as enablers but they note that these factors could be either enablers or barriers to access and engagement. Parents identified the importance of having individualized, supportive feedback from a professional with expertise in causes, or functions, of their child's challenging behaviour as well as having sessions that were affordable as well as being delivered in method and at a time that suited the family schedule.

\section{Synthesis of Results}

As described above, the studies investigating barriers to accessing services for mental health or behavioural challenges in individuals on the autism spectrum have used a diverse range of methodologies and measures. Despite this variety, a number of barriers to access were common across studies, as summarised in Table 3. Table 3 presents the studies by informant, so it is possible to explore the barriers reported for adult (via self-report studies) and children (via parent-report studies) separately. 
Table 3

Barriers to Access Services or Supports for Mental Health or Behaviour Reported Across Studies (listed in order of consistency of findings across studies)

\begin{tabular}{|c|c|c|c|c|c|c|c|c|c|c|c|c|}
\hline & \multirow{2}{*}{\multicolumn{6}{|c|}{$\begin{array}{c}\text { Adult self-report } \\
\text { Mental health }\end{array}$}} & \multicolumn{6}{|c|}{ Parent report } \\
\hline & & & & & & & \multicolumn{3}{|c|}{ Mental health } & \multicolumn{3}{|c|}{ Behaviour } \\
\hline & 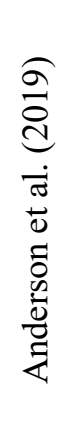 & 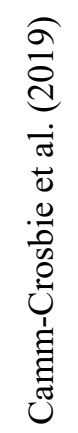 & $\begin{array}{l}\widehat{\sigma} \\
\stackrel{d}{d} \\
\dot{\sigma} \\
\tilde{d} \\
\tilde{d} \\
\stackrel{\pi}{0}\end{array}$ & 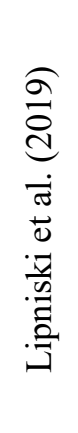 & 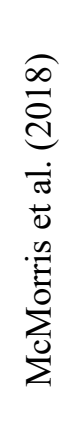 & 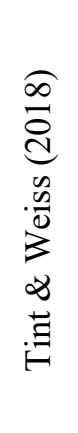 & 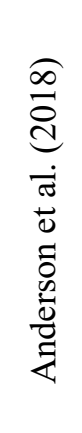 & 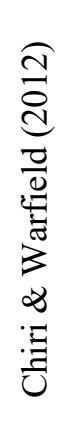 & 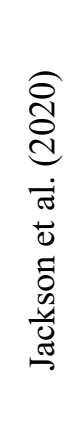 & $\begin{array}{l}\frac{\pi}{3} \\
\stackrel{d}{0} \\
\frac{\pi}{\sigma} \\
\frac{0}{0} \\
\frac{\pi}{0} \\
0 \\
0\end{array}$ & 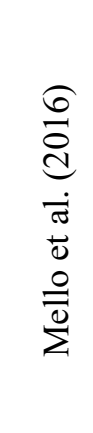 & 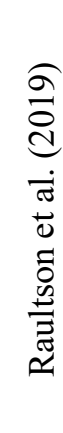 \\
\hline $\begin{array}{l}\text { Professional had a lack of autism knowledge or did not have expertise to treat } \\
\text { autism, therapist/service won't tailor approach to autism }\end{array}$ & & $\bullet$ & $\bullet$ & & & $\bullet$ & $\bullet$ & $\bullet$ & & & & $\bullet$ \\
\hline Long waiting list & & $\bullet$ & $\bullet$ & & & & & & $\bullet$ & & & \\
\hline $\begin{array}{l}\text { Not knowing how to or feeling confident to access, steps to access too } \\
\text { overwhelming or not able to do it in preferred way }\end{array}$ & $\bullet$ & $\bullet$ & & & $\bullet$ & & & $\bullet$ & & & & \\
\hline Cost/Funding/Insurance & & $\bullet$ & $\bullet$ & & & $\bullet$ & & $\bullet$ & & & & $\bullet$ \\
\hline $\begin{array}{l}\text { Not fitting in to service, not meeting service access criteria or bounced between } \\
\text { services }\end{array}$ & & $\bullet$ & & & & & $\bullet$ & & $\bullet$ & & & \\
\hline Not believed or not seen as severe enough & & • & $\bullet$ & & & & & & $\bullet$ & & & \\
\hline Service not available (in area) & $\bullet$ & & & & & & & $\bullet$ & & & $\bullet$ & \\
\hline Own communication challenges e.g., describing symptoms, problems, emotions & & $\bullet$ & & & $\bullet$ & & & & & & & \\
\hline Individual did not recognise the need for, or want, help & & • & & & • & & & & & & & \\
\hline Dissatisfaction with, or lack of trust in, service or therapist & & & & & & & & & • & & & \\
\hline Distance/Transport & & & & & & & & $\bullet$ & & $\bullet$ & & \\
\hline No time, impact of home/work/school schedule & & & & & & & & & & • & & 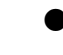 \\
\hline
\end{tabular}


The most frequently reported barrier to accessing services for mental health was the therapist having no or limited knowledge or experience of autism or therapists and services refusing to make alternations to treatments to support the individual on the spectrum. This was reported in four of the six adult self-report studies, using both quantitative (Lipinksi et al., 2019) and qualitative analysis (Camm-Crosbie et al., 2019; Crane et al., 2019; Tint \& Weiss, 2018), and in three parent-report studies (Anderson et al., 2018; Chiri \& Warfield, 2012; Raulston et al.). Long waiting lists were reported in five studies, being reported as a barrier to accessing mental health services in four adult self-report studies (Camm-Crosbie et al., 2019, Crane et al., 2019; Lipinski et al., 2019, McMorris et al., 2018) but only one parentreport study (Jackson et al., 2020). Another barrier which was reported predominantly by adults on the spectrum (rather than by parents) related to access: not knowing how or not feeling confident to access services, finding the steps to access services too overwhelming, or not being able to make initial contact in the preferred way. This was reported in four of the adult self-report studies (Anderson et al., 2019; Camm-Crosbie et al., 2019, Lipinski et al., 2019, McMorris et al., 2018) and in one parent-report study (Chiri \& Warfield, 2012).

Four barriers were reported by both individuals on the spectrum and by parents. Issues relating to the cost, funding of sessions, or coverage by insurance were noted, with those highlighting limited service funding predominantly being from the UK (Camm-Crosbie et al., 2019, Crane et al., 2019, Tint \& Weiss, 2018) and those relating to insurance being from the United States (Chiri \&Warfield, 2012; Raulston et al., 2019). Not meeting the entry criteria for a mental health service or being bounced between mental health and disability services was reported in two self-report (Camm-Crosbie et al., 2019, Crane et al., 2019) and two parent-report studies (Anderson et al., 2018; Jackson et al., 2020). Three studies reported that participants felt that their symptoms were not believed or that their symptoms were not seen as severe enough to warrant services (Camm-Crosbie et al., 2019; Chiri \& Warfield, 
2012; Crane et al., 2019) and three (Anderson et al., 2019; Chiri \& Warfield, 2012; Mello et al., 2016) reported that the specific services were not available, or not available in the local area (note that Mello et al., 2016, focused on services for behaviour).

Two barriers were reported only by adults on the autism spectrum. Having difficulties in communicating, and describing one's own symptoms, problems, and emotions, were identified in Camm-Crosbie et al. (2019), McMorris et al. (2018), and Tint and Weiss (2018). Challenges in recognising the need for help or individuals not wanting help and wanting to manage their symptoms independently were noted in two studies (Camm-Crosbie et al., 2019, McMorris et al., 2018). Three barriers were reported only by parents; a dissatisfaction or a lack of trust with the service or the therapist (Chiri \& Warfield, 2012; Jackson et al., 2020), the distance that would need to be travelled or other transport issues (Chiri \& Warfield, 2012; Hock et al., 2015) and, specifically around access to services for behaviour, a lack of available time amongst the busy home, work, and school schedules (Hock et al., 2015).

All of the six studies that reported facilitators to accessing services (Camm-Crosbie et al., 2019; Crane et al., 2019; Hock et al., 2015; Jackson et al., 2020; Lipinski et al., 2019; Raulston et al., 2019) highlighted therapist variables, the common of which was the continuity of therapist, sessions, and service provider (Camm-Crosbie et al., 2019; Crane et al., 2019; Jackson et al., 2020). Three studies reported on the importance of therapist adapting to meet the needs of an individual on the spectrum (Camm-Crosbie et al., 2019; Crane et al., 2019; Raulston et al., 2019) and two reported the facilitator of the therapist having knowledge of or a personal connection to autism (Camm-Crosbie et al., 2019, Hock et al., 2015).

\section{Discussion}

This review synthesized the findings from 12 studies reporting on barriers and/or facilitators to seeking and accessing help for mental health or behavioural problems in 
individuals on the autism spectrum. The most commonly reported barrier was a lack of therapist knowledge or expertise in autism or an inability or unwillingness to tailor approaches to support the needs of those on the autism spectrum. Other frequently reported barriers included service-related barriers (e.g., long waiting lists, not being able to access a service, and being "bounced" between mental health and disability services) as well as clientbased barriers (e.g., not knowing how to access services, poor emotional literacy of issues). Fewer studies identified facilitators to accessing services, of those that did, continuity of therapist and of service provision were most consistently reported.

\section{Barriers to Accessing Mental Health Services}

Nine studies reported upon the barriers for accessing treatment for mental health services. The barriers coincided with some of the overarching themes reported in Reardon et al.'s (2017) systematic review in typically developing children/adolescents. These included knowledge and understanding of mental health problems and the help-seeking process, and systemic and structural issues associated with the mental health system. In contrast to Reardon et al., none of the nine studies reported on barriers relating to family circumstances (e.g., time and effort involved, other responsibilities, support network, etc.) and none identified attitudes towards service providers and treatment as a barrier. The current review also highlighted a number of autism-specific barriers, including the professionals' lack of autism knowledge, unwillingness to make autism-specific adaptations, a lack of recognition or belief of mental health challenges, clients' communication challenges with identifying/describing symptoms, and being "bounced" between services.

Despite increasing prevalence rates, variability in levels of autism knowledge is well documented amongst a range of professionals including community mental health practitioners (Maddox et al., 2019), physicians (McCormack et al., 2019), allied health professionals (Atun-Einy \& Ben-Sasson, 2018), and teachers (Barned et al., 2011). Alongside 
a lack of knowledge, many professionals also report a lack of self-efficacy for working with individuals on the spectrum, including those working in community mental health services (Brookman-Frazee et al., 2012). Whilst self-perceived autism knowledge and self-efficacy of working with individuals on the spectrum may not always be directly related to actual experience of working with individuals on the spectrum (Schwartz \& Drager, 2008), AtunEiny and Ben-Sasson (2018) found a positive effect of experience on actual autism knowledge. This led them to conclude that clinical exposure strengthens knowledge more than does clinical education. The consistent reporting of therapists' low levels of autism knowledge and/or low self-efficacy for working with individuals on the spectrum highlights this as a priority area for change. Given that training alone may not be enough to bring about meaningful change in clinician behaviour (e.g. Maddox et al., 2019), clinicians may also need effective supervision from an experienced practitioner and/or an adult on the autism spectrum as a critical autism expert (as per Gillespie-Lynch et al., 2017).

Patient-led approaches to therapy are intrinsic in most clinical training. Ensuring an environment that is considerate to sensory issues, allowing written forms of communication between sessions, keeping consistent times, rooms, and formats, and setting up clear expectations for each session are the same as those suggested for physical health-care appointments (Nicolaidis et al., 2013). These can be incorporated into therapy regardless of the therapeutic approach used. Autism-specific adaptations to the therapy itself have been previously published for adolescents and adults on the autism spectrum (e.g., White et al., 2018). A systematic review (Walters et al., 2016) and a recent Delphi study (Spain \& Happe, 2019) have also suggested accommodations for children. However, given that a significant barrier was funding of sessions and that in several studies, participants spoke of being discharged due to funding limitations before feeling fully better, the extent to which the 
therapeutic process can be adjusted in real-world settings (rather than in a research trial) may differ between countries and publicly versus privately funded services.

The barrier of a lack of recognition, or belief of, the mental health challenges being experienced by individuals on the spectrum may be suggestive of diagnostic overshadowing; a phenomenon well documented in both the autism and intellectual disability (e.g., Jopp \& Keys, 2001) as well as the wider literature (Shefer et al., 2014). Diagnostic overshadowing refers to the misattribution of symptoms (in this case, mental health symptoms) to another diagnosis that the person has (in this case, their autism); for example, not seeing social anxiety symptoms as they are interpreted as a consequence of a skill deficit related to the profile of autism characteristics (Adams, MacDonald, \& Keen, 2019).

Given the relative recency of increased autism-specific anxiety research (Vasa et al., 2018), many clinicians may not feel confident in making informed decisions about what are age-appropriate or autism-related behaviours and what are normal variations of behaviour and/or mental health within the context of autism. Of course, this therapist-related barrier may be linked to the client-related barrier of communication challenges; for example, individuals on the spectrum having challenges in identifying and/or describing symptoms, problems, or emotions. Challenges in interoception (detection of internal states, including emotions) and alexithymia (difficulties in expressing emotions), both of which are higher in individuals on the spectrum than in neurotypical individuals (DuBois et al., 2016; Kinnaird et al., 2019) and are reported by practitioners to impact upon the therapeutic process (Ainsworth et al., 2020), may also make it more difficult to identify mental health symptomatology. There may also be a potential impact of masking, camouflaging, or "putting on your best normal" (Crane et al., 2019). In a system where individuals (or their parents) have to advocate for referrals and access to services, these factors could limit the extent to which needs are recognised, explained, or understood. There is also a possibility of them the 
interacting with other barriers identified, such as a lack of knowledge of autism characteristics, diagnostic overshadowing and potentially limitations of funding and therapist availability, to create significant barriers to accessing mental health services. There have been some developments and positive evaluations of tools for individuals to complete prior to healthcare appointments to help them prepare, self-advocate, and communicate their current physical health challenges and symptoms (along with other information) in a clear and concise way (e.g., Bultas et al., 2016; Nicolaidis et al., 2016). Such a tool, which should be co-developed with those on the spectrum, would also be beneficial in mental health and would be important to evaluate in future, longitudinal research. This may also begin to address the barrier of being "bounced" between mental health and intellectual disability services.

\section{Barriers to Behavioural Supports}

Although there were a number of studies documenting the predictors of or the effectiveness of services for behavioural challenges in individuals on the autism spectrum, this review identified only three studies specifically reporting on barriers to access. Unsurprisingly, given the intensity of some behavioural approaches, a lack of time and problems fitting around pre-existing schedules was identified as a barrier; one that was not noted for any of the mental health focussed studies. A review of the factors influencing parental decisions of any interventions (Carlon et al., 2013) noted that time was a factor in five of the studies. Birkin et al. (2008) reported that almost $40 \%$ of parents did not enrol in the National Autistic Society's Earlybird program as it was not available at a time that worked with their schedule. Ensuring that interventions are feasible and accessible to parents is critical to allow for interventions to be implemented and to be effective at reducing behavioural challenges. The possibility of conducting therapy sessions over telehealth would address both of the barriers identified for the behavioural interventions as it would increase 
geographical availability and reduce the time required for travel, arrangements for childcare, and so on. Lindgren et al. (2016) found comparable reductions in child behavioural challenges $(>90 \%)$ when delivering applied behaviour analysis parent training through faceto-face, clinic-based telehealth and home-based telehealth methods. A systematic review of telehealth as a model for providing behavioural interventions to reduce behavioural challenges in individuals on the autism spectrum noted favourable outcomes in all studies, but noted the need for more quality research in the area (Ferguson et al., 2019).

\section{Facilitators to Accessing Services}

Only six studies documented facilitators or enablers to accessing services, all of which related to the therapist or service, rather than the individual on the spectrum or their parent. The most frequently noted facilitator across studies was the consistency of therapist, sessions, and service provider. The challenges associated with transitioning between different healthcare providers and services is well documented but despite this, such transitions or changes are often not prepared for or effectively supported (Kuhlthau et al., 2015). The openness of the provider to considering accommodations is also noted as a facilitator to accessing physical healthcare. Nicolaidis et al. (2015) suggested that the willingness and ability of therapists to modify their own behaviour to meet patient needs and treat them with respect is a true demonstration of emotional or social reciprocity.

\section{Implications and Areas for Future Research}

This review highlights several key areas of intervention to reduce the presence and/or impact of barriers to accessing psychological support for mental health or for emotional or behavioural challenges for individuals on the spectrum. Firstly, the lack of autism knowledge amongst therapists was the most frequently perceived barrier to accessing mental health services. This is unsurprising given that mental healthcare professionals report limited training, knowledge, or tools to accommodate individuals on the spectrum (Brookman-Frazee 
et al., 2012; Zerbo et al., 2015) and that 70\% of mental healthcare professionals rate their ability to provide healthcare for this population as poor or fair (Zerbo et al., 2015). It is important that specialist training for all healthcare professionals is accessible (Crane et al., 2019; Nicolaidis et al., 2013) and frequently updated. Individuals on the autism spectrum and their family members should feel confident that the professionals providing treatment understand their unique challenges, are knowledgeable about autism and mental health difficulties, and are able to bridge the link between the two (Crane et al., 2019). Furthermore, increased professional knowledge and training is likely to reduce the amount these individuals are "bounced" between services.

Secondly, raising awareness of the range of services available and ensuring that accessing such services is via a transparent (and if needed, supported) way will reduce barriers experienced around knowing where and how to seek support. In addition, greater awareness surrounding autism and mental health difficulties may help to reduce stigma and misunderstandings about autism and assist with fostering positive attitudes towards the benefits of psychological treatment (McMorris et al., 2018). As indicated by Mason et al. (2019), healthcare professionals are in the position to alleviate this difficulty for their clients by providing accurate and concise signposting to relevant services.

Thirdly, professionals need to be open to adapting to the individualised needs of their patients and making appropriate accommodations (Camm-Crosbie et al., 2019). Nicolaidis et al. (2015) highlighted several autism-specific factors affecting interactions in healthcare generally (i.e., not specific to mental health). These included sensory sensitivities, verbal and non-verbal communication challenges, cognitive challenges (slowed processing speed and poor organisation), and possible challenges with intereoception and alexithymia. Accommodating for these factors is essential for bridging the significant disparities in healthcare outcomes between individuals with and without autism (Nicolaidis et al., 2013). It 
may be that offering initial consultations or even ongoing therapy over telehealth could help to reduce the barriers to access. The events of 2020 have resulted in a range of professionals having to move to telehealth models to deliver their interventions, which may further inform and enhance telehealth evaluations and delivery models into the future.

The current review highlights many gaps for future research. Specifically, only three studies examined the barriers and facilitators for accessing behaviour supports for individuals on the spectrum and only six studies examined the facilitators for accessing treatment for mental health or behavioural problems. More work is needed to explore both the barriers to access and the barriers to continued engagement in therapy. This can then help ensure that once an individual on the spectrum or their parent has managed to access therapy, they feel comfortable continuing with it and that it is as effective as possible at meeting the goals set. As has been noted in a recent systematic review of selection bias on intellectual ability in autism research (Russell, Mandy et al., 2019), there was a lack of studies which included individuals with an intellectual disability and no studies that reported on the experiences of older adults on the spectrum. Finally, there is an absence of self-report studies from the perspective of children and adolescents on the autism spectrum. Given that mental health symptoms are present in children on the spectrum from as young as 5 years old (Keen et al., 2019), continuing through the primary years (Adams et al., 2018) and into secondary school (den Houting et al., 2018), it is likely that children on the spectrum will be accessing therapy themselves. Exploring the factors that help and hinder them in attending and engaging in such sessions will be an important piece of work for ensuring that therapies provided are accessible and effective for individuals on the spectrum across the lifespan.

\section{Limitations of this Review}

The small number of studies in the area is notable when compared to the 44 studies reported upon in Reardon et al.'s (2017) review, which reported only upon parent-perceived 
barriers in typically developing children (i.e., no self-report and no adult studies). This limited research combined with the recency of the included articles, highlights that exploring the experiences of those accessing (or trying to access) psychological supports is in its early stages within the autism research field. Only studies published in the English language were included within the current review, limiting reference to those studies from a wider range of countries that may be conducting research on this topic. Furthermore, barriers and facilitators may have been discussed in other studies, including the grey literature, that were not identified by the key search terms used within the current review. The keywords may not have identified all relevant literature, so future reviews should extend the terms to include broader terms relating to behaviour (such as challenging behavio*).

\section{Conclusion}

Individuals on the spectrum are more likely to experience physical and mental health concerns. While developing treatments should remain a priority, ensuring and supporting access to these treatments is critical if they are to be effective in real-world settings. The current review identified 12 studies that investigated the barriers and facilitators for accessing mental health and emotional/behavioural services for individuals on the autism spectrum. The available literature highlights the need for autism-specific considerations in order to increase access to services. These include increased specialist training for healthcare professionals, patient-led approaches and individualised accommodations, and increased awareness of the range of services available. The small number of studies in this area emphasises the need for further research, particularly pertaining to barriers and facilitators to accessing behavioural supports and the inclusion of a more diverse range of participants (including individuals on the autism spectrum across the lifespan and those with intellectual disability). 


\section{References}

Adams, D., Clark, M., \& Keen, D. (2019). Using self-report to explore the relationship between anxiety and quality of life in children on the autism spectrum. Autism Research, 12(10), 1505-1515. doi:10.1002/aur.2155

Adams, D., MacDonald, L., \& Keen, D. (2019). Teacher responses to anxiety-related behaviours in students on the autism spectrum. Research in Developmental Disabilities, 86, 11-19. doi:10.1016/j.ridd.2018.12.009

Adams, D., Simpson, K., \& Keen, D. (2018). School-related anxiety symptomatology in a community sample of primary-school-aged children on the autism spectrum. Journal of School Psychology, 70, 64-73. doi:10.1016/j.jsp.2018.07.003

Adams, D., Young, K., Simpson, K., \& Keen, D. (2019). Parent descriptions of the presentation and management of anxiousness in children on the autism spectrum. Autism, 23(4), 980-992. doi:10.1177/1362361318794031

Ainsworth, K., Robertson, A. E., Welsh, H., Day, M., Watt, J., Barry, F., Stanfield, A., \& Melville, C. (2020). Anxiety in adults with autism: Perspectives from practitioners. Research in Autism Spectrum Disorders, 69, 101457. doi:10.1016/j.rasd.2019.101457

American Psychiatric Association. (2013). Diagnostic and Statistical Manual of Mental Disorders (DSM-5®). American Psychiatric Pub.

Anderson, A. H., Carter, M., \& Stephenson, J. (2019). An on-line survey of university students with autism spectrum disorder in Australia and New Zealand: Characteristics, support satisfaction, and advocacy. Journal of Autism \& Developmental Disorders, 50(2), 440-454. Doi: 10.1007/s10803-019-04259-8

Anderson, C., Lupfer, A., \& Shattuck, P. T. (2018). Barriers to receipt of services for young adults with autism. Pediatrics, 141(Suppl 4), S300-S305. doi: 10.1542/peds.2016$4300 \mathrm{~g}$ 
Atun-Einy, O., \& Ben-Sasson, A. (2018). Pediatric allied healthcare professionals' knowledge and self-efficacy regarding ASD. Research in Autism Spectrum Disorders, 47, 1-13. doi:10.1016/j.rasd.2017.12.001

Ayres, M., Parr, J. R., Rodgers, J., Mason, D., Avery, L., \& Flynn, D. (2018). A systematic review of quality of life of adults on the autism spectrum. Autism, 22(7), 774-783. doi:10.1177/1362361317714988

Barned, N. E., Knapp, N. F., \& Neuharth-Pritchett, S. (2011). Knowledge and attitudes of early childhood preservice teachers regarding the inclusion of children with autism spectrum disorder. Journal of Early Childhood Teacher Education, 32(4), 302-321. doi:10.1080/10901027.2011.622235

Ben-Sasson, A., Atun-Einy, O., Yahav-Jonas, G., Lev-On, S., \& Gev, T. (2018). Training physical therapists in early ASD screening. Journal of Autism and Developmental Disorders, 48(11), 3926-3938. doi:10.1007/s10803-018-3668-9

Birkin, C., Anderson, A., Seymour, F., \& Moore, D. W. (2008). A parent-focused early intervention program for autism: Who gets access? Journal of Intellectual and Developmental Disability, 33(2), 108-116. doi:10.1080/13668250802036746

Brookman-Frazee, L., Drahota, A., Stadnick, N., \& Palinkas, L. A. (2012). Therapist perspectives on community mental health services for children with autism spectrum disorders. Administration and Policy in Mental Health and Mental Health Services Research, 39(5), 365-373. doi:10.1007/s10488-011-0355-y

Bultas, M. W., McMillin, S. E., \& Zand, D. H. (2016). Reducing barriers to care in the officebased health care setting for children with autism. Journal of Pediatric Health Care, 30(1), 5-14. doi:10.1016/j.pedhc.2015.08.007 
Byrne, G., Ghráda, Á. N., O’Mahony, T., \& Brennan, E. (2020). A systematic review of the use of acceptance and commitment therapy in supporting parents. Psychology and Psychotherapy: Theory, Research and Practice. doi:10.1111/papt.12282

Camm-Crosbie, L., Bradley, L., Shaw, R., Baron-Cohen, S., \& Cassidy, S. (2019). 'People like me don't get support': Autistic adults' experiences of support and treatment for mental health difficulties, self-injury and suicidality. Autism, 23(6), 1431-1441. doi: $10.1177 / 1362361318816053$

Carlon, S., Carter, M., \& Stephenson, J. (2013). A review of declared factors identified by parents of children with autism spectrum disorders (ASD) in making intervention decisions. Research in Autism Spectrum Disorders, 7(2), 369-381. doi: 10.1016/j.rasd.2012.10.009

Chiri, G., \& Warfield, M. E. (2012). Unmet need and problems accessing core health care services for children with autism spectrum disorder. Maternal and Child Health Journal, 16(5), 1081-1091. doi:10.1007/s10995-011-0833-6

Commonwealth Fund (2020, September 4). International Health Care System Profiles 2020. https://www.commonwealthfund.org/international-health-policy-center/countries

Crane, L., Adams, F., Harper, G., Welch, J., \& Pellicano, E. (2019). 'Something needs to change': Mental health experiences of young autistic adults in England. Autism, 23(2), 477-493. doi:10.1177/1362361318757048

den Houting, J., Adams, D., Roberts, J., \& Keen, D. (2018). Exploring anxiety symptomatology in school-aged autistic children using an autism-specific assessment. Research in Autism Spectrum Disorders, 50, 73-82. doi:10.1016/j.rasd.2018.03.005 den Houting, J., Adams, D., Roberts, J., \& Keen, D. (2020). Brief Report: Investigating the Impact of Anxious Symptomatology in Autistic Children. International Journal of 
Disability, Development and Education, ePub ahead of Print.

doi:10.1080/1034912X.2020.1727420

DuBois, D., Ameis, S. H., Lai, M. C., Casanova, M. F., \& Desarkar, P. (2016). Interoception in Autism Spectrum Disorder: A review. International Journal of Developmental Neuroscience, 52, 104-111. doi:10.1016/j.ijdevneu.2016.05.001

Ferguson, J., Craig, E. A., \& Dounavi, K. (2019). Telehealth as a model for providing behaviour analytic interventions to individuals with autism spectrum disorder: A systematic review. Journal of Autism and Developmental Disorders, 49(2), 582-616. doi:10.1007/s10803-018-3724-5

Fortuna, R. J., Robinson, L., Smith, T. H., Meccarello, J., Bullen, B., Nobis, K., \& Davidson, P. W. (2016). Health conditions and functional status in adults with autism: A crosssectional evaluation. Journal of General Internal Medicine, 31(1), 77-84. doi:10.1007/s11606-015-3509-x

Gaigg, S. B., Flaxman, P. E., McLaven, G., Shah, R., Bowler, D. M., Meyer, B., Roestorf, C. H., Rodgers, J., \& South, M. (2020). Self-guided mindfulness and cognitive behavioural practices reduce anxiety in autistic adults: A pilot 8-month waitlistcontrolled trial of widely available online tools. Autism, 1362361320909184. doi:10.1177/1362361320909184

Gillespie-Lynch, K., Kapp, S. K., Brooks, P. J., Pickens, J., \& Schwartzman, B. (2017). Whose expertise is it? Evidence for autistic adults as critical autism experts. Frontiers in Psychology, 8, 438. doi:10.3389/fpsyg.2017.00438

Hock, R., Yingling, M. E., \& Kinsman, A. (2015). A parent-informed framework of treatment engagement in group-based interventions. Journal of Child and Family Studies, 24(11), 3372-3382. doi:10.1007/s10826-015-0139-1 
Hollocks, M. J., Lerh, J. W., Magiati, I., Meiser-Stedman, R., \& Brugha, T. S. (2019). Anxiety and depression in adults with autism spectrum disorder: A systematic review and meta-analysis. Psychological Medicine, 49(4), 559-572. doi:10.1017/S0033291718002283

Hudson, C. C., Hall, L., \& Harkness, K. L. (2019). Prevalence of depressive disorders in individuals with autism spectrum disorder: A meta-analysis. Journal of Abnormal Child Psychology, 47(1), 165-175. doi:10.1007/s10802-018-0402-1

Jackson, L., Keville, S., \& Ludlow, A. K. (2020). Mothers' Experiences of Accessing Mental Health Care for their Child with an Autism Spectrum Disorder. Journal of Child and Family Studies, 29(2), 534-545. doi:10.1007/s10826-019-01662-8

Jackson, C. \& Cheater, F. M. \& Reid, I. (2008) A systematic review of decision support needs of parents making child health decisions. Health Expectations, 11, 232-251. https://doi.org: 10.1111/j.1369-7625. 2008.00496.x

Jopp, D. A., \& Keys, C. B. (2001). Diagnostic overshadowing reviewed and reconsidered. American Journal of Mental Retardation, 106(5), 416-433. doi:10.1352/08958017(2001)106<0416:DORAR>2.0.CO;2

Keen, D., Adams, D., Simpson, K., den Houting, J., \& Roberts, J. (2019). Anxiety-related symptomatology in young children on the autism spectrum. Autism, 23(2), 350-358. doi:10.1177/1362361317734692

Kinnaird, E., Stewart, C., \& Tchanturia, K. (2019). Investigating alexithymia in autism: A systematic review and meta-analysis. European Psychiatry, 55, 80-89. doi:10.1016/j.eurpsy.2018.09.004

Kohn, R., Saxena, S., Levav, I., \& Saraceno, B. (2004). The treatment gap in mental health care. Bulletin of the World Health Organization, 82(11), 858-866. doi:/S004296862004001100011 
Kreslins, A., Robertson, A. E., \& Melville, C. (2015). The effectiveness of psychosocial interventions for anxiety in children and adolescents with autism spectrum disorder: A systematic review and meta-analysis. Child and Adolescent Psychiatry and Mental Health, 9, 22. doi:10.1186/s13034-015-0054-7

Kuhlthau, K. A., Warfield, M. E., Hurson, J., Delahaye, J., \& Crossman, M. K. (2015). Pediatric provider's perspectives on the transition to adult health care for youth with autism spectrum disorder: Current strategies and promising new directions. Autism, 19(3), 262-271. doi:10.1177/1362361313518125

Lai, M. C., Kassee, C., Besney, R., Bonato, S., Hull, L., Mandy, W., Szatmari, P., \& Ameis, S. H. (2019). Prevalence of co-occurring mental health diagnoses in the autism population: a systematic review and meta-analysis. Lancet Psychiatry, 6(10), 819829. doi:10.1016/S2215-0366(19)30289-5

Lindgren, S., Wacker, D., Suess, A., Schieltz, K., Pelzel, K., Kopelman, T., Lee, J., Romani, P., \& Waldron, D. (2016). Telehealth and autism: Treating challenging behavior at lower cost. Pediatrics, 137 Suppl 2, S167-175. doi:10.1542/peds.2015-2851O

Lipinski, S., Blanke, E. S., Suenkel, U., \& Dziobek, I. (2019). Outpatient psychotherapy for adults with high-functioning autism spectrum condition: Utilization, treatment satisfaction, and preferred modifications. Journal of Autism \& Developmental Disorders, 49(3), 1154-1168. doi: 10.1007/s10803-018-3797-1

Maddox, B. B., Crabbe, S., Beidas, R. S., Brookman-Frazee, L., Cannuscio, C. C., Miller, J. S., Nicolaidis, C., \& Mandell, D. S. (2019). "I wouldn't know where to start": Perspectives from clinicians, agency leaders, and autistic adults on improving community mental health services for autistic adults. Autism, 1362361319882227. doi: $10.1177 / 1362361319882227$ 
Mason, D., Ingham, B., Urbanowicz, A., Michael, C., Birtles, H., Woodbury-Smith, M., Brown, T., James, I., Scarlett, C., Nicolaidis, C., \& Parr, J. R. (2019). A systematic review of what barriers and facilitators prevent and enable physical healthcare services access for autistic adults. Journal of Autism and Developmental Disorders, 49(8), 3387-3400. doi:10.1007/s10803-019-04049-2

Mason, D., Mackintosh, J., McConachie, H., Rodgers, J., Finch, T., \& Parr, J. R. (2019). Quality of life for older autistic people: The impact of mental health difficulties. Research in Autism Spectrum Disorders, 63, 13-22. doi: 10.1016/j.rasd.2019.02.007

McBain, R. K., Kareddy, V., Cantor, J. H., Stein, B. D., \& Yu, H. (2020). Systematic Review: United States Workforce for Autism-Related Child Healthcare Services. Journal of the American Academy of Child \& Adolescent Psychiatry, 59(1), 113-139. doi:10.1016/j.jaac.2019.04.027

McCormack, G., Dillon, A. C., Healy, O., Walsh, C., \& Lydon, S. (2019). Primary Care Physicians' Knowledge of Autism and Evidence-Based Interventions for Autism: A Systematic Review. Review Journal of Autism and Developmental Disorders, 7(3), 226-241. doi:10.1007/s40489-019-00189-4

McGillivray, J. A., \& Evert, H. T. (2014). Group cognitive behavioural therapy program shows potential in reducing symptoms of depression and stress among young people with ASD. Journal of Autism and Developmental Disorders, 44(8), 2041-2051. doi:10.1007/s10803-014-2087-9

McMorris, C. A., Baraskewich, J., Ames, M. A., Shaikh, K. T., Ncube, B. L., \& Bebko, J. M. (2018). Mental health issues in post-secondary students with autism spectrum disorder: Experiences in accessing services. International Journal of Mental Health and Addiction. doi:10.1007/s11469-018-9988-3 
Mello, M. P., Goldman, S. E., Urbano, R. C., \& Hodapp, R. M. (2016). Services for children with autism spectrum disorder: Comparing rural and non-rural communities. Education and Training in Autism and Developmental Disabilities, 51(4), 355-365.

Nicolaidis, C., Raymaker, D. M., Ashkenazy, E., McDonald, K. E., Dern, S., Baggs, A. E., Gerrity, M., Kripke, C., Platt, L., \& Baggs, A. (2015). "Respect the way I need to communicate with you": Healthcare experiences of adults on the autism spectrum. Autism, 19(7), 824-831. doi: 10.1177/1362361315576221

Nicolaidis, C., Raymaker, D., McDonald, K., Dern, S., Boisclair, W. C., Ashkenazy, E., \& Baggs, A. (2013). Comparison of healthcare experiences in autistic and non-autistic adults: A cross-sectional online survey facilitated by an academic-community partnership. Journal of General Internal Medicine, 28(6), 761-769. doi:10.1007/s11606-012-2262-7

Nicolaidis, C., Raymaker, D., McDonald, K., Kapp, S., Weiner, M., Ashkenazy, E., Gerrity, M., Kripke, C., Platt, L., \& Baggs, A. (2016). The development and evaluation of an online healthcare toolkit for autistic adults and their primary care providers. Journal of General Internal Medicine, 31(10), 1180-1189. doi:10.1007/s11606-016-3763-6

Petticrew, M., \& Roberts, H. (2008). Systematic reviews in the social sciences: A practical guide. John Wiley \& Sons.

Polanczyk, G. V., Salum, G. A., Sugaya, L. S., Caye, A., \& Rohde, L. A. (2015). Annual research review: A meta-analysis of the worldwide prevalence of mental disorders in children and adolescents. Journal of Child Psychology and Psychiatry, 56(3), 345365. doi:10.1111/jcpp.12381

Raulston, T. J., Hieneman, M., Caraway, N., Pennefather, J., \& Bhana, N. (2019). Enablers of behavioral parent training for families of children with autism spectrum disorder. 
Journal of Child and Family Studies, 28(3), 693-703. doi: 10.1007/s10826-018-1295-

$\mathrm{X}$

Reardon, T., Harvey, K., Baranowska, M., O'Brien, D., Smith, L., \& Creswell, C. (2017). What do parents perceive are the barriers and facilitators to accessing psychological treatment for mental health problems in children and adolescents? A systematic review of qualitative and quantitative studies. European Child \& Adolescent Psychiatry, 26(6), 623-647. doi:10.1007/s00787-016-0930-6

Robertson, A. E., Stanfield, A. C., Watt, J., Barry, F., Day, M., Cormack, M., \& Melville, C. (2018). The experience and impact of anxiety in autistic adults: A thematic analysis. Research in Autism Spectrum Disorders, 46, 8-18. doi: 10.1016/j.rasd.2017.11.006

Russell, A., Cooper, K., Barton, S., Ensum, I., Gaunt, D., Horwood, J., Ingham, B., Kessler, D., Metcalfe, C., Parr, J., Raj, D., \& Wiles, N. (2017). Protocol for a feasibility study and randomised pilot trial of a low-intensity psychological intervention for depression in adults with autism: The Autism Depression Trial (ADEPT). BMJ Open, 7(12), e019545. doi:10.1136/bmjopen-2017-019545

Russell, A., Gaunt, D., Cooper, K., Horwood, J., Barton, S., Ensum, I., Ingham, B., Parr, J., Metcalf, C., Kessler, D., \& Wiles, N. (2019). Guided self-help for depression in autistic adults: The ADEPT feasibility RCT. Health Technology Assessment, 23(68), 1-94. doi:10.3310/hta23680

Russell, G., Mandy, W., Elliott, D., White, R., Pittwood, T., \& Ford, T. (2019). Selection bias on intellectual ability in autism research: A cross-sectional review and meta-analysis. Molecular Autism, 10, 9. doi:10.1186/s13229-019-0260-х 
Santomauro, D., Sheffield, J., \& Sofronoff, K. (2016). Depression in adolescents with ASD: A pilot RCT of a group intervention. Journal of Autism and Developmental Disorders, 46(2), 572-588. doi: 10.1007/s10803-015-2605-4

Sawyer, M. G., Reece, C. E., Sawyer, A. C., Hiscock, H., \& Lawrence, D. (2019). Adequacy of treatment for child and adolescent mental disorders in Australia: A national study. Australian and New Zealand Journal of Psychiatry, 53(4), 326-335. doi:10.1177/0004867418808895

Schwartz, H., \& Drager, K. D. (2008). Training and knowledge in autism among speechlanguage pathologists: A survey. Language, Speech, and Hearing Services in Schools, 39(1), 66-77. doi:10.1044/0161-1461(2008/007)

Schott, W., Nonnemacher, S., \& Shea, L. (2020). Service Use and Unmet Needs Among Adults with Autism Awaiting Home- and Community-Based Medicaid Services. Journal of Autism and Developmental Disorders. doi:10.1007/s10803-020$04593-2$

Shefer, G., Henderson, C., Howard, L. M., Murray, J., \& Thornicroft, G. (2014). Diagnostic overshadowing and other challenges involved in the diagnostic process of patients with mental illness who present in emergency departments with physical symptoms--a qualitative study. PLoS One, 9(11), e111682. doi:10.1371/journal.pone.0111682

Sirriyeh, R., Lawton, R., Gardner, P., \& Armitage, G. (2012). Reviewing studies with diverse designs: The development and evaluation of a new tool. Journal of Evaluation in Clinical Practice, 18(4), 746-752. doi:10.1111/j.1365-2753.2011.01662.x

Sizoo, B. B., \& Kuiper, E. (2017). Cognitive behavioural therapy and mindfulness based stress reduction may be equally effective in reducing anxiety and depression in adults with autism spectrum disorders. Research in Developmental Disabilities, 64, 47-55. doi:10.1016/j.ridd.2017.03.004 
Spain, D., \& Happé, F. (2019). How to optimise cognitive behaviour therapy (CBT) for people with autism spectrum disorders (ASD): A Delphi study. Journal of RationalEmotive \& Cognitive-Behavior Therapy, 1-25. doi:10.1007/s10942-019-00335-1

Steel, Z., Marnane, C., Iranpour, C., Chey, T., Jackson, J. W., Patel, V., \& Silove, D. (2014). The global prevalence of common mental disorders: A systematic review and metaanalysis 1980-2013. International Journal of Epidemiology, 43(2), 476-493. doi:10.1093/ije/dyu038

Sukhodolsky, D. G., Bloch, M. H., Panza, K. E., \& Reichow, B. (2013). Cognitive-behavioral therapy for anxiety in children with high-functioning autism: A meta-analysis. Pediatrics, 132(5), e1341-e1350. doi: 10.1542/peds.2013-1193

Taylor, J. L., \& Henninger, N. A. (2014). Frequency and Correlates of Service Access Among Youth with Autism Transitioning to Adulthood. Journal of Autism and Developmental Disorders, 45(1), 179-191. doi:10.1007/s10803-014-2203-x

Tint, A., \& Weiss, J. A. (2018). A qualitative study of the service experiences of women with autism spectrum disorder. Autism, 22(8), 928-937. doi:10.1177/1362361317702561

Ung, D., Selles, R., Small, B. J., \& Storch, E. A. (2015). A systematic review and metaanalysis of cognitive-behavioral therapy for anxiety in youth with high-functioning autism spectrum disorders. Child Psychiatry \& Human Development, 46(4), 533-547. doi:10.1007/s10578-014-0494-y

Van Steensel, F. J., Bögels, S. M., \& Perrin, S. (2011). Anxiety disorders in children and adolescents with autistic spectrum disorders: A meta-analysis. Clinical Child and Family Psychology Review, 14(3), 302. doi: 10.1007/s10567-011-0097-0

Vasa, R. A., Keefer, A., Reaven, J., South, M., \& White, S. W. (2018). Priorities for advancing research on youth with autism spectrum disorder and co-occurring anxiety. 
Journal of Autism and Developmental Disorders, 48(3), 925-934. doi:

$10.1007 / \mathrm{s} 10803-017-3320-0$

Walters, S., Loades, M., \& Russell, A. (2016). A systematic review of effective modifications to cognitive behavioural therapy for young people with autism spectrum disorders. Review Journal of Autism and Developmental Disorders, 3(2), 137-153. doi: $10.1007 / \mathrm{s} 40489-016-0072-2$

Weiss, J. A., Isaacs, B., Diepstra, H., Wilton, A. S., Brown, H. K., McGarry, C., \& Lunsky, Y. (2018). Health concerns and health service utilization in a population cohort of young adults with autism spectrum disorder. Journal of Autism and Developmental Disorders, 48(1), 36-44. doi:10.1007/s10803-017-3292-0

Weston, L., Hodgekins, J., \& Langdon, P. E. (2016). Effectiveness of cognitive behavioural therapy with people who have autistic spectrum disorders: A systematic review and meta-analysis. Clinical Psychology Review, 49, 41-54. doi:10.1016/j.cpr.2016.08.001

White, S. W., Simmons, G. L., Gotham, K. O., Conner, C. M., Smith, I. C., Beck, K. B., \& Mazefsky, C. A. (2018). Psychosocial treatments targeting anxiety and depression in adolescents and adults on the autism spectrum: Review of the latest research and recommended future directions. Current Psychiatry Reports, 20(10), 82. doi:10.1007/s11920-018-0949-0

Wolfenden, C., Wittkowski, A., \& Hare, D. J. (2017). Symptoms of Autism Spectrum Disorder (ASD) in Individuals with Mucopolysaccharide Disease Type III (Sanfilippo Syndrome): A Systematic Review. Journal of Autism and Developmental Disorders, 47(11), 3620-3633. doi:10.1007/s10803-017-3262-6

Whittle, E., Fishers, J., Reppermund, S., Lenroot, R. \& Trollor, J. (2018). Barriers and enablers to accessing mental health services for people with intellectual disability: A 
scoping review. Journal of Mental Health Research in Intellectual Disabilities, 11(1), 69-102, doi:10.1080/19315864.2017.1408724

Zerbo, O., Massolo, M. L., Qian, Y., \& Croen, L. A. (2015). A study of physician knowledge and experience with autism in adults in a large integrated healthcare system. Journal of Autism and Developmental Disorders, 45(12), 4002-4014. doi:10.1007/s10803$015-2579-2$

Zerbo, O., Qian, Y., Ray, T., Sidney, S., Rich, S., Massolo, M., \& Croen, L. A. (2019). Health care service utilization and cost among adults with autism spectrum disorders in a US integrated health care system. Autism in Adulthood, 1(1), 27-36. doi: 10.1089/aut.2018.0004 